\title{
Protease inhibitor concentrations in the saliva of individuals experiencing oral dryness
}

Kenkichi Yamamoto ${ }^{1 *}$, Makiko Hiraishi ${ }^{1}$, Mai Haneoka ${ }^{2}$, Hidetake Fujinaka' ${ }^{1}$ and Yoshitaka Yano ${ }^{1}$

\begin{abstract}
Background: Oral dryness is a common symptom that may interfere with swallowing, chewing, and taste. The most common reason for oral dryness is hyposalivation. Some individuals experiencing oral dryness do not have hyposalivation, however, and the reverse is also true. Here, we focused on healthy individuals with a lower salivary flow rate and evaluated the relationship between the perception of oral dryness and salivary parameters to clarify the cause underlying the perception of oral dryness.
\end{abstract}

Methods: A total of 59 participants were divided into 2 groups with a lower or higher salivary flow rate according to the median salivary flow rate. In participants with a lower salivary flow rate, we assessed salivary bacterial counts, protease activities, protein concentrations, oral parameters, and the subjective perception of oral dryness.

Results: Protease activities and concentrations of protease inhibitors such as cystatin-D and cystatin-SA in the saliva of participants experiencing oral dryness were significantly higher and lower, respectively, than in those not experiencing oral dryness, even though no difference in the salivary flow rate was detected. Salivary cystatin-D and cystatinSA concentrations correlated negatively with salivary protease activities.

Conclusions: The composition of salivary protease inhibitors and increased protease activities affect the subjective perception of oral dryness.

Keywords: Salivary cystatins, Peptide hydrolases, Oral dryness, Xerostomia, Humans

\section{Introduction}

Saliva is important for oral health. Major saliva-producing glands include the parotid, submandibular, and sublingual glands, but minor glands located beneath the oral mucosa also contribute to salivary levels. Oral disease and discomfort may result from oral dryness. The subjective perception of oral dryness, or xerostomia, is not always associated with objectively lower salivary secretion levels [1]. The most common reasons for xerostomia are hyposalivation due to oral or systemic disease [2], head and

\footnotetext{
*Correspondence: yamamoto.kenkichi@kao.com

1 Personal Health Care Products Research Laboratories, Kao Corporation,

2-1-3 Bunka, Sumida-ku, Tokyo 131-8501, Japan

Full list of author information is available at the end of the article
}

neck radiotherapy [3], and certain medication [4]. Hyposalivation leads to an increased risk of dental caries or periodontitis, oral mucosa or tongue pain, and bacterial and fungal infections [5]. Several studies [6-8] have demonstrated a correlation between the whole salivary secretion rate and the perception of oral dryness, whereas others have not $[9,10]$. In addition to hyposalivation, oral dryness can be caused by dehydration and mouth breathing [11]. The experience of oral dryness may also relate to the contribution of minor salivary glands present throughout the oral cavity, since minor labial salivary gland secretion rates were reduced among individuals with subjective oral dryness $[12,13]$. Accumulation of plaque and an increase in the number of bacteria in the saliva could be 
expected when the salivary secretion rate is low. Lactobacilli, Candida and Streptococcus mitis were increased in the saliva of the individuals with xerostomia $[14,15]$.

Saliva contains an abundance of proteins, including mucin, histatin, cystatin, statherin, amylase, and prolinerich protein. These proteins are essential for maintaining tooth and mucosal integrity, and are also involved in digestion, lubrication, buffering, and antibacterial activity [16]. Several studies have evaluated changes in salivary protein levels in individuals experiencing oral dryness. Pramanik et al. [17] reported that mucins on the anterior tongue were reduced in patients with dry mouth. Mizuhashi et al. [18] reported reduced rates of the antimicrobial proteins lactoferrin and chromogranin $\mathrm{A}$ in those experiencing oral dryness. These studies, however, focused on individuals with hyposalivation experiencing oral dryness, and it is unclear whether changes in the salivary protein levels are also observed in individuals without hyposalivation but still experiencing oral dryness.

The present study, therefore, evaluated whether salivary proteins influence the perception of oral dryness in systemically healthy subjects. The subjective perception of oral dryness was examined in relation to clinical, oral, bacterial, and salivary parameters.

\section{Methods and materials \\ Study participants}

A total of 59 healthy male Japanese volunteers aged 31 to 57 years (mean $45.7 \pm 6.2$ ) participated in the study. Participants were recruited as volunteers from among employees of the Kao Corporation in Japan. All participants responded to a questionnaire regarding medication intake and general medical data. Only healthy individuals without systemic disorders or metabolic diseases were included in the study. As described below in detail, resting whole saliva was collected under the same conditions for each individual. We then divided the subjects into 2 groups: those with a lower salivary flow rate $(n=30)$ and those with a higher salivary flow rate $(n=29)$ on the basis of the overall median salivary flow rate. Participants with a lower salivary flow rate were used as study subjects. Women were not included because salivary flow rates can be influenced by the menstrual cycle [19]. All participants provided written informed consent prior to their participation in the study. The Ethics Committee of the Kao Corporation approved the study (approval number:12-10), which followed the tenets of the Declaration of Helsinki.

\section{Clinical and oral discomfort assessment}

All experiments were performed between 8:30 AM and 11:30 AM. From the test day to the end of the test session, participants were asked to avoid activities that might influence salivary flow (e.g., eating, drinking, gargling, toothbrushing, and smoking). Participants were also asked not to consume alcohol for at least $12 \mathrm{~h}$ before starting the experiments. Clinical parameters of both dental and gingival health were assessed by routine methods. Decaying, missing, and filled teeth were recorded. In addition, the gingival index, bleeding on probing, probing depth, and oral hygiene index were determined as described previously [20-23]. The Winkel tongue coating index was used to score the degree of tongue coating [24]. Volatile sulfur compounds were assessed using a portable sulfide monitor (MS-Halimeter E, Interscan Corporation, Simi Valley, CA) [25]. To assess oral dryness perception, we used the following oral dryness question (with a YES/NO response option) based on the study by Farsi [26]: "Does your mouth feel dry?".

\section{Collection of saliva samples}

Subjects rinsed their mouths thoroughly with $6 \mathrm{~mL}$ of water before saliva collection. The oral rinsing water was collected to measure turbidity at the optical density of $660 \mathrm{~nm}(\mathrm{OD} 660 \mathrm{~nm})$ using a Sunrise ${ }^{\mathrm{TM}}$ microplate reader (Tecan Trading AG, Männedorf, Switzerland). Mucosal detachments were measured by centrifuging the oral rinsing solution $\left(15,000 \mathrm{rpm}\right.$ for $15 \mathrm{~min}$ at $\left.4{ }^{\circ} \mathrm{C}\right)$ and then measuring the wet weight of the pellet after decanting the supernatant. Resting whole saliva was collected with subjects in the seated position; subjects were asked to expectorate directly into a sterile container for $10 \mathrm{~min}$. The volume of saliva (in grams) collected over the 10-min period was used to calculate the salivary flow rate $(\mathrm{g} /$ min). The samples were analyzed immediately for bacterial counts as described below, followed by clearance by centrifugation $\left(3000 \mathrm{rpm}\right.$ for $15 \mathrm{~min}$ at $4{ }^{\circ} \mathrm{C}$ ) and storage at $-80^{\circ} \mathrm{C}$ until assayed.

\section{Biochemical and microbial analysis of saliva}

The protein concentration of the resting saliva was determined using a Coomassie reagent-staining assay, using BSA as a standard. $5 \mu \mathrm{L}$ of 5 -times diluted saliva supernatant was pipetted into a clear flat-bottom 96 well plate and $250 \mu \mathrm{L}$ of Advanced Protein Assay Reagent (Cytoskeleton Inc., Denver, $\mathrm{CO}$ ) was added and mixed. The absorbances at 595 and $450 \mathrm{~nm}$ were measured. The data were processed using the ratio of the absorbance at $595 \mathrm{~nm}$ to that at $450 \mathrm{~nm}$ for all samples. Enzymatic activity of saliva, such as protease activity, was assayed using the synthetic substrate Boc-Phe-Ser-Arg-MCA (t-butyloxycarbonyl-Lphenylalanyl-L-seryl-L-arginine4-methyl-7-coumarylamide (Peptide Institute Incorporated, Osaka, Japan); final conc. $100 \mu \mathrm{M}$ in dimethyl sulfoxide) $[27,28]$ in sodium phosphate buffer ( $\mathrm{pH}$ 7.0). $100 \mu \mathrm{L}$ of saliva supernatant was incubated at $37{ }^{\circ} \mathrm{C}$ for 10 min with $100 \mu \mathrm{L}$ sodium 
phosphate buffer containing the synthetic substrate. After incubation, 7-amino-4-methylcoumarin (AMC) was measured at $460 \mathrm{~nm}$ (excitation at $380 \mathrm{~nm}$ ), using AMC (Peptide Institute Incorporated, Osaka, Japan) as a standard. We defined 1 unit of enzyme activity as the amount of enzyme that produced $1 \mu \mathrm{M}$ of $\mathrm{AMC} / \mathrm{mL}$. Salivary bacterial counts were measured using a bacteria counter (Panasonic, Osaka, Japan), using the dielectrophoresis and impedance measurement method [29]. The assays were all performed according to the manufacturers' instructions.

\section{Identification of saliva proteins by mass spectrometry}

For ultrafiltration, saliva samples were diluted with $100 \mathrm{mM}$ Tris/HCl buffer ( $\mathrm{pH}$ 8.0), transferred to a 3-kDacutoff Millipore ultrafiltration device (Merck KGaA, Darmstadt, Germany), and centrifuged at $15,000 \mathrm{rpm}$ at $4{ }^{\circ} \mathrm{C}$ for $30 \mathrm{~min} .100 \mathrm{mM}$ Tris/ $\mathrm{HCl}$ buffer $(\mathrm{pH} 8.0)$ was transferred to the 3-kDa-cutoff Millipore ultrafiltration device 3 times to wash the retentate. The protein concentration of concentrated saliva was determined using the Advanced Protein Assay. Saliva samples were diluted with $100 \mathrm{mM}$ Tris/ $\mathrm{HCl}$ buffer to obtain equal amounts of protein. Briefly, $90 \mu \mathrm{L}$ aliquots were reduced by mixing with $100 \mathrm{mM}$ dithiothreitol at $57{ }^{\circ} \mathrm{C}$ and incubated for $45 \mathrm{~min}$. The mixture was then alkylated with $0.6 \mathrm{mM}$ iodoacetamide in the dark and at room temperature for $30 \mathrm{~min}$. The samples were then digested with sequencing grade-modified trypsin $(1: 20[\mathrm{w} / \mathrm{w}]$ enzyme to substrate ratio; Promega, Madison, WI) at $37{ }^{\circ} \mathrm{C}$ for $19 \mathrm{~h}$. Finally, formic acid (final concentration $0.3 \%$ ) was added to terminate the digest.

Mass spectrometric identification of proteins was performed by a previously described method with modification [30]. Briefly, peptide analysis was performed using liquid chromatography-mass spectrometry (LC-MS; LC: Ultimate 3000 RSLCnano System, Dionex, Sunnyvale, CA; MS: quadrupole time-of-flight mass spectrometer, Triple $\mathrm{TOF}^{\circledR} 5600+$, AB SCIEX, Framingham, MA). The tryptic digests $(1 \mu \mathrm{g}$ of total protein from each saliva sample) were loaded onto an Acclaim PepMap 100 Nano Trap C18 $(75 \mu \mathrm{m} \times 20 \mathrm{~mm}$; particle size $3 \mu \mathrm{m}$, nanoViper, Dionex) at a flow rate of $5 \mu \mathrm{L} / \mathrm{min}$ for 5 min using $0.1 \%$ trifluoroacetic acid, and separated with nanoAcquity UPLC BEH130 C18 $(100 \mu \mathrm{m} \times 100 \mathrm{~mm}$, particle size $1.7 \mu \mathrm{m}$, Waters, Milford, MA) at a flow rate of $400 \mathrm{~nL} / \mathrm{min}$. Mobile phases consisted of A $(0.1 \%$ formic acid) and B (80\% acetonitrile/20\% water containing $0.1 \%$ formic acid). A linear gradient of $2 \%$ to $50 \%$ B over 120 min was used throughout the study. Instrument control and data acquisition (information-dependent acquisition) were performed with Analyst TF 1.6 software (AB SCIEX, Framingham, MA). The ESI voltage was $2300 \mathrm{~V}$, the interface temperature was $150{ }^{\circ} \mathrm{C}$, and the declustering potential was $80 \mathrm{~V}$. In an informationdependent acquisition cycle, one MS scan was performed for $250 \mathrm{~ms}$, and a maximum of 20 ions with an intensity greater than $150 \mathrm{cps}$ and charge states of 2, 3, 4, and 5 were selected for MS/MS scans with an accumulation time of $100 \mathrm{~ms}$. The scan ranges were $\mathrm{m} / z 350$ to 1250 for MS and $m / z 100$ to 2000 for MS/MS. The raw data for each sample were processed using Protein Pilot software 4.5 (AB SCIEX, Framingham, MA) to generate the MGF file.

\section{Database search and protein identification}

The Mascot version 2.3 database search engine (Matrix Science, Chicago, IL) was used for protein identification against the Swiss-Prot protein database (http:// www.uniprot.org/). We performed database searches for the carbamidomethylation of cysteine as a fixed modification and oxidation of methionine as a variable modification. Enzyme specificity was set to trypsin, and the allowed number of missed cleavages was set to 1 . MS tolerances were $20 \mathrm{ppm}$ for the precursor and 20 $\mathrm{mmu}$ for the fragment ions. The positive protein identification criteria were confidence levels $>99 \%$. Mascot's automatic decoy searches were performed to estimate the false discovery rate (FDR). Briefly, each time a protein sequence from the Swiss-Prot database was tested, a reversed decoy sequence of the same length was automatically generated and tested. The FDR was calculated as $\mathrm{FDR}=\mathrm{FP} /(\mathrm{FP}+\mathrm{TP})$, where $\mathrm{FP}$ and $\mathrm{TP}$ are false and true positive matches, respectively. The number of peptides matches in the target database is $\mathrm{FP}+\mathrm{TP}$ and number of peptides matches in the decoy database is FP. In all proteomic analyses, an FDR $<1 \%$ was used as an identity threshold. Protein contents in molar percentages were calculated by the exponentially modified protein abundance index (emPAI), as described by Ishihama et al. [30]. Salivary antileukoproteinase and cystatins concentrations were calculated by multiplying emPAI by the total protein concentration (emPAI*mg/ $\mathrm{mL})$.

\section{Statistical analysis}

Difference between values, such as salivary protease activity, salivary protein concentration, and oral parameters, in the oral dryness group and the control group were statistically analyzed using the Mann-Whitney U test. The correlations between salivary protease activities and salivary cystatins were examined using the Spearman correlation coefficient. A $p$-value less than 0.05 was considered statistically significant. BellCurve for Excel 
(Social Survey Research Information, Tokyo, Japan) was used for the statistical analyses.

\section{Results}

\section{Resting whole salivary flow secretion}

Resting whole salivary flow rates of 59 subjects are shown in dot plots, with a median of $0.40 \mathrm{~g} / \mathrm{min}$ (Fig. 1). We then divided the subjects into 2 groups: those with a lower salivary flow rate $(n=30)$ and those with a higher salivary flow rate $(n=29)$ on the basis of the overall median salivary flow rate. Subsequent assessment was conducted in subjects with a lower salivary flow rate. The mean flow rate of lower salivary flow rate

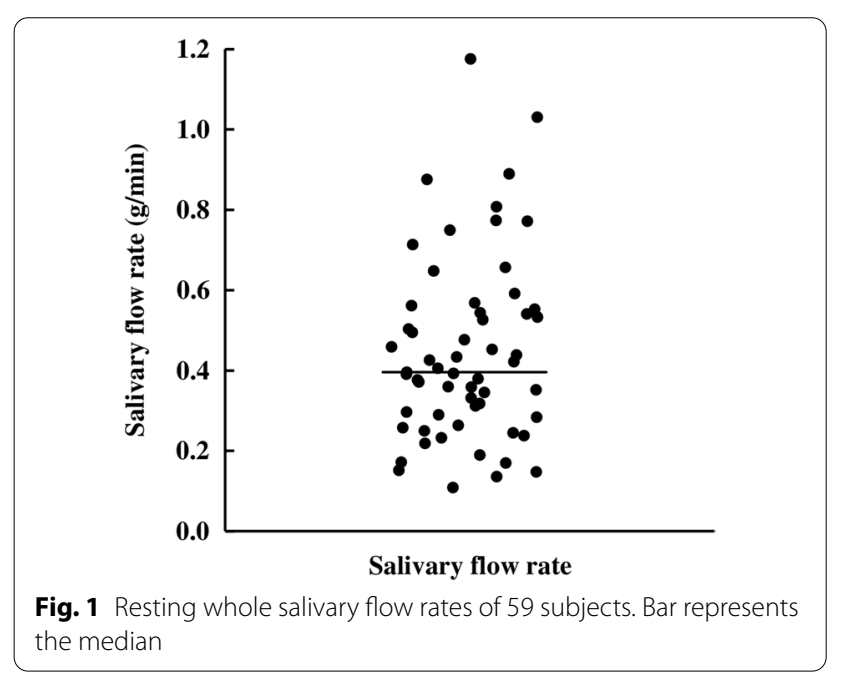

group and higher salivary flow rate group were 0.28 and $0.62 \mathrm{~g} / \mathrm{min}$, respectively.

\section{Comparison of clinical and oral parameters in subjects with and without subjective perceptions of oral dryness}

We administered questionnaires to subjects with a lower salivary flow rate to assess the subjective perception of oral dryness. On this basis, the subjects were divided into 2 groups, 9 individuals who experienced oral dryness (oral dryness group) and 21 individuals who did not (control group). We next determined the salivary flow rate in the 2 groups (Table 1). No significant difference in the mean salivary flow rate was detected between the groups: $0.25 \pm 0.08$ and $0.29 \pm 0.09 \mathrm{~g} / \mathrm{min}$ in the oral dryness and the control groups, respectively. Because there was no difference in the salivary flow rate between the 2 groups, we next examined the clinical and oral parameters. The clinical and oral parameters are shown in Table 1. The oral dryness group had significantly higher salivary protease activities compared with the control group (Fig. 2). The median salivary protease activity in the control group and oral dryness group were 2.2 and 3.3 units, respectively. The oral dryness group also had significantly higher bleeding on probing and gingival index compared with the control group (Table 1).

\section{Salivary protease inhibitors in subjects with and without subjective perceptions of oral dryness}

Because the protease activities varied among the oral dryness symptom groups, we next examined the concentrations of salivary protease inhibitors by peptide

Table 1 Comparison of oral parameters in subjects with and without the perception of oral dryness

\begin{tabular}{|c|c|c|}
\hline & Control group $(n=21)$ & $\begin{array}{l}\text { Oral dryness } \\
\text { group }(n=9)\end{array}$ \\
\hline Age & $45.8 \pm 6.6$ & $45.1 \pm 5.9$ \\
\hline Saliva flow rate (g/min) & $0.29 \pm 0.09$ & $0.25 \pm 0.08$ \\
\hline Salivary protein concentration $(\mathrm{mg} / \mathrm{mL})$ & $0.74 \pm 0.46$ & $0.62 \pm 0.30$ \\
\hline Salivary bacterial counts (logCFU/mL) & $6.19 \pm 0.48$ & $6.30 \pm 0.39$ \\
\hline Oral rinsing solution turbidity $\left(\mathrm{OD}_{660}\right)$ & $0.25 \pm 0.13$ & $0.33 \pm 0.10$ \\
\hline Mucosal detachment (mg) & $7.7 \pm 2.5$ & $9.5 \pm 2.7$ \\
\hline DMFT & $12.0 \pm 6.6$ & $12.4 \pm 6.5$ \\
\hline $\mathrm{Gl}$ & $0.93 \pm 0.15$ & $1.06 \pm 0.10^{*}$ \\
\hline $\mathrm{BOP}$ & $0.08 \pm 0.08$ & $0.16 \pm 0.10^{*}$ \\
\hline $\mathrm{PD}(\mathrm{mm})$ & $2.50 \pm 0.18$ & $2.66 \pm 0.28$ \\
\hline $\mathrm{OHI}$ & $1.78 \pm 0.91$ & $2.11 \pm 0.77$ \\
\hline WTCl & $1.95 \pm 2.29$ & $3.44 \pm 2.46$ \\
\hline VSC (ppb) & $229 \pm 144$ & $228 \pm 106$ \\
\hline
\end{tabular}

Values are shown as the mean \pm SD. Mann-Whitney $U$ test, vs control; * $p<0.05$

$B O P$ bleeding on probing; CFU colony forming units; DMFT decayed, missing, and filled teeth; GI gingival index; $O D$ optical density; $O H I$ oral hygiene index; $P D$ probing depth; VSC volatile sulfur compounds; WTCI Winkel tongue coating index 


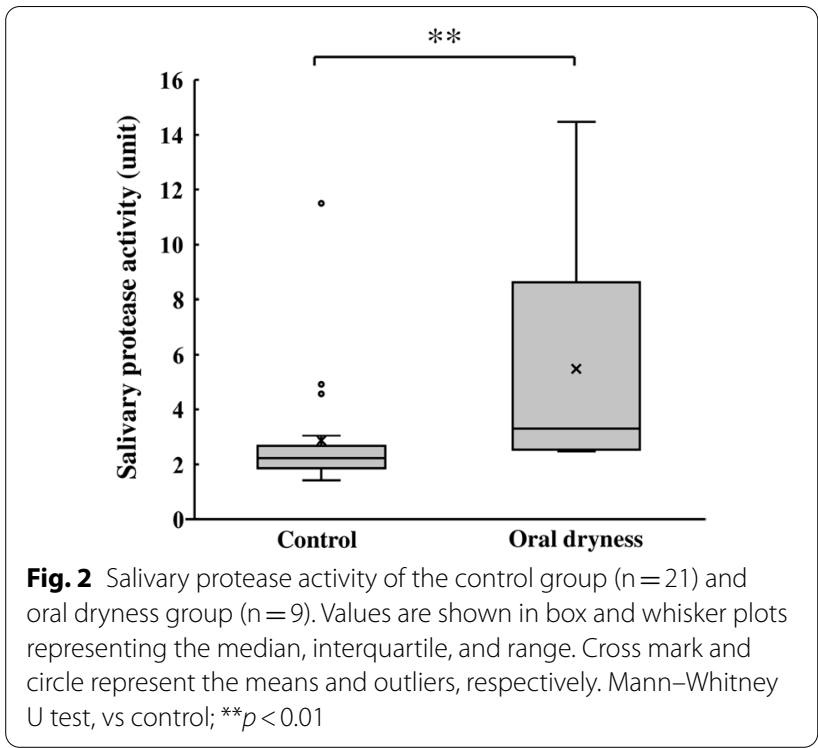

analysis using LC-MS. Saliva samples from each group were assessed for the concentrations of salivary protease inhibitory proteins such as antileukoproteinase and the cysteine protease inhibitors, cystatin- $B,-C$, -D, -S, -SA, and -SN. Salivary cystatin-D and -SA concentrations were significantly lower in the oral dryness group than in the control group (Fig. 3). The median salivary cystatin-D and cystatin-SA concentrations in the control group were 1.11 and $2.28 \mathrm{emPAI} * \mathrm{mg} / \mathrm{mL}$, respectively, whereas those in the oral dryness group

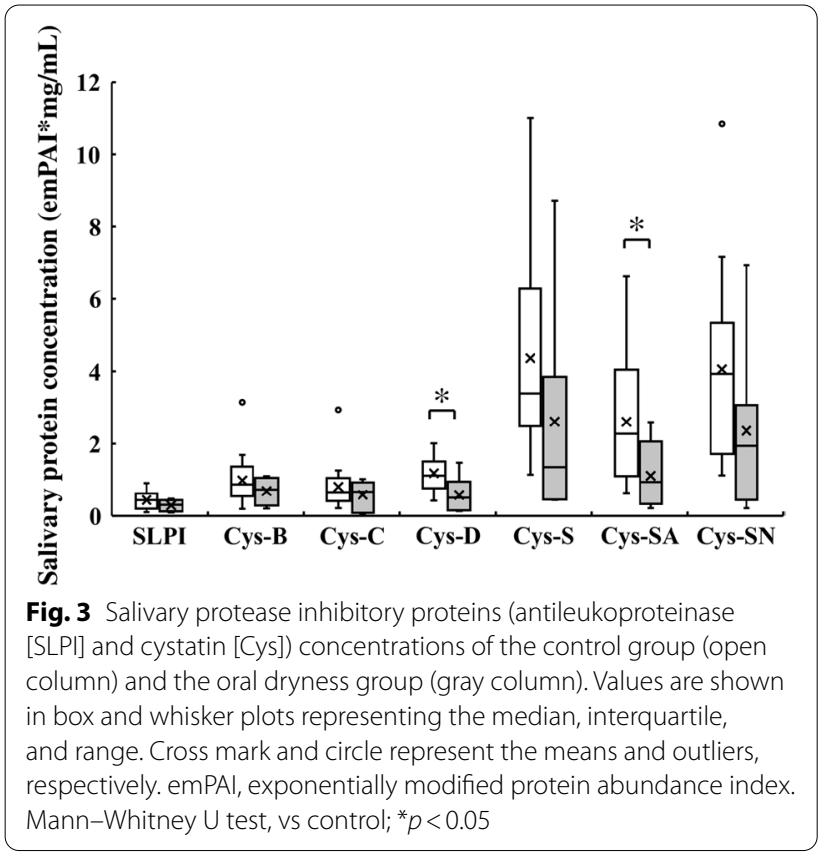

were 0.50 and 0.93 emPAI"mg/mL, respectively. The oral dryness group tended to have lower concentrations of salivary antileukoproteinase, and cystatin-B, - C, -S, and $-\mathrm{SN}$, although the differences between the 2 groups were not significant.

\section{Correlations of salivary protease activity and salivary protein inhibitors}

Because salivary protease activities and salivary protease inhibitors concentrations changed inversely in each group, we next examined the correlations of salivary protease activities and concentrations of salivary protein inhibitors. Salivary cystatin-D and cystatin-SA concentrations were significantly negatively correlated with salivary protease activities (Fig. 4a, b).

\section{Discussion}

In the present study, we focused on systemically healthy individuals with relatively lower salivary flow rates to evaluate whether they experienced oral dryness. On the

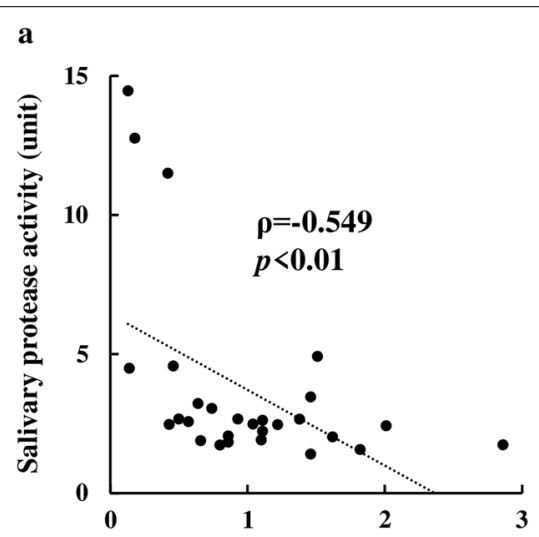

Salivary Cys-D concentration (emPAI*mg/mL)

b

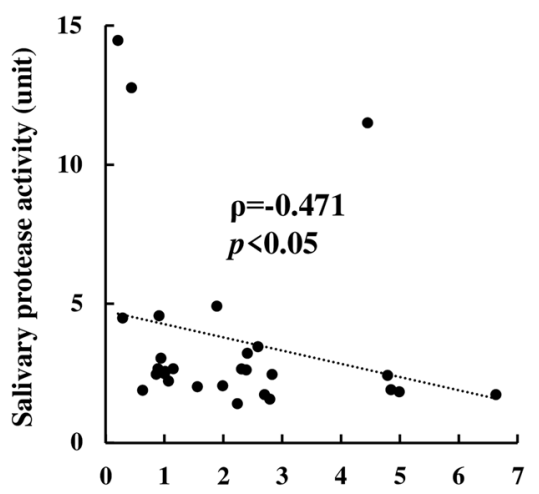

Salivary Cys-SA concentration (emPAI*mg/mL)

Fig. 4 Spearman rank correlation coefficient ( $\rho$ ) of salivary protease activity and salivary a Cys-D, or $\mathbf{b}$ Cys-SA concentrations in 30 subjects. emPAl exponentially modified protein abundance index 
basis of whether they experienced oral dryness, the subjects were separated into 2 groups, those with and without the subjective perception of oral dryness. The salivary flow rate did not differ between the 2 groups. Unstimulated salivary flow rate is approximately $0.3-0.4 \mathrm{~mL} / \mathrm{min}$ in normal humans, whereas the unstimulated salivary flow rate in those with hyposalivation is $\leq 0.1 \mathrm{~mL} / \mathrm{min}$ [31-33]. In the present study, none of the subjects had an unstimulated salivary flow below $0.1 \mathrm{~g} / \mathrm{min}$, indicating that none of the subjects had hyposalivation. Previous studies mentioned that some individuals experience oral dryness even when the salivary secretion rate is normal $[9,10]$. Therefore, the underlying cause of the perception of oral dryness was thought to be an issue other than a decrease in the salivary flow rate.

We found that salivary protease activities were higher in subjects experiencing oral dryness than those not experiencing oral dryness. We further demonstrated that the salivary cystatin-D and -SA concentrations were lower in the oral dryness subjects than in the control subjects. The concentrations of salivary cystatin-D and cystatin-SA showed significant negative correlations with salivary protease activities. These observations suggest that activation of proteases caused by the reduction of inhibitory protease expression is involved in the perception of oral dryness.

The mechanism underlying the perception of oral dryness is complicated. Analysis of clinical parameters revealed that gingival index and bleeding on probing in subjects experiencing oral dryness were significantly higher than in those not experiencing oral dryness. Cystatins have antimicrobial and protease inhibitory properties [34,35]. Therefore, it is likely that the build-up of periodontitis-associated bacteria on the gingiva occurs, leading to gingival inflammations in the subjects with low concentrations of salivary protease inhibitors. Porphyromonas gingivalis is an anaerobic gram-negative bacterium frequently isolated from advanced periodontal lesions [36]. P. gingivalis has 2 major cysteine proteinases, Arg-specific gingipain and Lys-specific gingipain [27], which possess an extracellular matrices decomposition function, such as type I and IV collagen, fibronectin, and laminin [27, 37]. Because human salivary cystatin-SA exhibits antimicrobial effects against the $P$. gingivalis [34], such a decomposition of the extracellular matrix caused by low levels of cystatins, including cystatin-SA, in saliva appears to be associated with the perception of oral dryness. Oral hygiene products containing antimicrobial proteins have been reported to reduce gingival inflammation and mucosal irritation, and to improve the subjective symptoms of dry mouth in patients with xerostomia [3841]. Oral mucosal conditions may lead to a perception of oral dryness, although further studies are needed.
This study has a few limitations. First, the number of participants was relatively small. While a larger sample would have been desirable, the fact that there was sufficient difference to obtain statistical significance indicated that the sample size was at least adequate for the analysis to find large differences with a limited sample size. The second, the participants were limited to the lower salivary flow rate subjects. Finally, the identification of salivary protein by MS was not validated using immunochemistry technique, such as western blot or ELISA. Within limitations, this study identified the composition of salivary protease inhibitors and increased protease activities affect the subjective perception of oral dryness. This study can serve as a baseline observation for future comprehensive studies, which could identify the role of salivary protease inhibitors in the perception of oral dryness.

\section{Conclusions}

Low concentrations of protease inhibitors such as cystatin-D and cystatin-SA were detected by LC-MS in the saliva of healthy individuals who experienced oral dryness. The composition of salivary protease inhibitors and increased protease activities affect the subjective perception of oral dryness. Control of salivary protease activities appears to be necessary for improvement of the quality of life of individuals experiencing oral dryness.

\section{Abbreviations}

LC-MS: Liquid chromatography-mass spectrometry; FDR: False discovery rate; emPAl: Exponentially modified protein abundance index.

\section{Acknowledgements}

We would like to thank Dr. Hiroshi Sugiya of Nihon University for helpful discussions and revising the manuscript. We also thank the members of Personal Health Care Products Research Laboratories and Analytical Science Research Laboratories, Kao Corporation for supporting the study. We are grateful to all the volunteer participants who participated in our study.

\section{Authors' contributions}

Conceptualization: KY, MH (Makiko Hiraishi), HF; Methodology: KY, MH, MH2 (Mai Haneoka); Formal analysis: $\mathrm{KY}, \mathrm{MH}$; Investigation: $\mathrm{KY}, \mathrm{MH}, \mathrm{MH} 2$; Writingoriginal draft preparation: $\mathrm{KY}, \mathrm{MH2}$; Writing-review \& editing: $\mathrm{KY}$; Supervision: HF, YY; Project administration: YY. All authors have read and approved the final manuscript.

\section{Funding}

This study was fully funded by Kao Corporation, Japan.

Availability of data and materials

The datasets obtained and analyzed during the current study are available from the corresponding author on reasonable request.

\section{Declarations}

Ethics approval and consent to participate

All participants provided written informed consent prior to their participation in the study. The Ethics Committee of the Kao Corporation approved the 
study (approval number:12-10), which followed the tenets of the Declaration of Helsinki.

\section{Consent for publication}

Not applicable.

\section{Competing interests}

The authors declare that they have no competing interests.

\section{Author details}

${ }_{1}^{1}$ Personal Health Care Products Research Laboratories, Kao Corporation, 2-1-3 Bunka, Sumida-ku, Tokyo 131-8501, Japan. ${ }^{2}$ Analytical Science Research Laboratories, Kao Corporation, Tochigi, Japan.

\section{Received: 17 September 2021 Accepted: 12 December 2021}

Published online: 20 December 2021

\section{References}

1. Napeñas JJ, Brennan MT, Fox PC. Diagnosis and treatment of xerostomia (dry mouth). Odontology. 2009;97:76-83.

2. Vitali C, Bombardieri S, Moutsopoulos HM, Balestrieri G, Bencivelli W, Bernstein RM, et al. Preliminary criteria for the classification of Sjögren's syndrome. Results of a prospective concerted action supported by the European Community. Arthritis Rheum. 1993;36:340-7.

3. Franzén L, Funegård U, Ericson T, Henriksson R. Parotid gland function during and following radiotherapy of malignancies in the head and neck. A consecutive study of salivary flow and patient discomfort. Eur J Cancer Oxf Engl. 1990;1992(28):457-62.

4. Nederfors T, Nauntofte B, Twetman S. Effects of furosemide and bendroflumethiazide on saliva flow rate and composition. Arch Oral Biol. 2004;49:507-13.

5. Soto-Rojas AE, Kraus A. The oral side of Sjögren syndrome. Diagnosis and treatment. A review. Arch Med Res. 2002;33:95-106.

6. Bardow A, Nyvad B, Nauntofte B. Relationships between medication intake, complaints of dry mouth, salivary flow rate and composition, and the rate of tooth demineralization in situ. Arch Oral Biol. 2001;46:413-23.

7. Suh K-I, Lee J-Y, Chung J-W, Kim Y-K, Kho H-S. Relationship between salivary flow rate and clinical symptoms and behaviours in patients with dry mouth. J Oral Rehabil. 2007;34:739-44.

8. van den Berg I, Pijpe J, Vissink A. Salivary gland parameters and clinical data related to the underlying disorder in patients with persisting xerostomia. Eur J Oral Sci. 2007;115:97-102.

9. Billings RJ, Proskin HM, Moss ME. Xerostomia and associated factors in a community-dwelling adult population. Commun Dent Oral Epidemiol. 1996:24:312-6.

10. Thorselius I, Emilson CG, Osterberg T. Salivary conditions and drug consumption in older age groups of elderly Swedish individuals. Gerodontics. 1988;4:66-70

11. Närhi TO. Prevalence of subjective feelings of dry mouth in the elderly. J Dent Res. 1994;73:20-5

12. Eliasson L, Birkhed D, Carlén A. Feeling of dry mouth in relation to whole and minor gland saliva secretion rate. Arch Oral Biol. 2009;54:263-7.

13. Inamura T, Ino C, Katoh M, Kishimoto A, Kumazawa H, Matsumoto A, et al. A simple method to estimate the secretion of saliva from minor salivary glands using iodine-starch reaction. Laryngoscope. 2001;111:272-7.

14. Weerkamp AH, Wagner K, Vissink A, Gravenmade EJ. Effect of the application of a mucin-based saliva substitute on the oral microflora of xerostomic patients. J Oral Pathol. 1987;16:474-8.

15. Almståhl A, Wikström M. Oral microflora in subjects with reduced salivary secretion. J Dent Res. 1999;78:1410-6.

16. Lamkin MS, Oppenheim FG. Structural features of salivary function. Crit Rev Oral Biol Med Off Publ Am Assoc Oral Biol. 1993;4:251-9.

17. Pramanik R, Osailan SM, Challacombe SJ, Urquhart D, Proctor GB. Protein and mucin retention on oral mucosal surfaces in dry mouth patients. Eur J Oral Sci. 2010;118:245-53.

18. Mizuhashi F, Koide K, Toya S, Takahashi M, Mizuhashi R, Shimomura H. Levels of the antimicrobial proteins lactoferrin and chromogranin in the saliva of individuals with oral dryness. J Prosthet Dent. 2015;113:35-8.

19. Kullander S, Sonesson B. Studies on saliva in menstruating, pregnant and postmenopausal women. Acta Endocrinol (Copenh). 1965;48:329-36.
20. Loe H, Silness J. Periodontal disease in pregnancy. I. Prevalence and severity. Acta Odontol Scand. 1963;21:533-51.

21. Löe H. The Gingival Index, the Plaque Index and the Retention Index Systems. J Periodontol. 1967;38(Suppl):610-6.

22. Organization WH. Oral health surveys : basic methods. World Health Organization; 1997. https://apps.who.int/iris/handle/10665/41905. Accessed 9 Feb 2021.

23. Greene JG, Vermillion JR. The Simplified Oral Hygiene Index. J Am Dent Assoc. 1964:68:7-13.

24. Winkel EG, Roldán S, Van Winkelhoff AJ, Herrera D, Sanz M. Clinical effects of a new mouthrinse containing chlorhexidine, cetylpyridinium chloride and zinclactate on oral halitosis. A dual-center, double-blind placebo-controlled study. J Clin Periodontol. 2003;30:300-6.

25. Rosenberg M, Kulkarni GV, Bosy A, McCulloch CA. Reproducibility and sensitivity of oral malodor measurements with a portable sulphide monitor. J Dent Res. 1991;70:1436-40.

26. Farsi NMA. Signs of oral dryness in relation to salivary flow rate, $\mathrm{pH}$, buffering capacity and dry mouth complaints. BMC Oral Health. 2007;7:15.

27. Kadowaki T, Yoneda M, Okamoto K, Maeda K, Yamamoto K. Purification and characterization of a novel arginine-specific cysteine proteinase (argingipain) involved in the pathogenesis of periodontal disease from the culture supernatant of Porphyromonas gingivalis. J Biol Chem. 1994;269:21371-8.

28. Molla A, Yamamoto T, Maeda H. Characterization of $73 \mathrm{kDa}$ thiol protease from Serratia marcescens and its effect on plasma proteins. J Biochem (Tokyo). 1988;104:616-21.

29. Hamada R, Suehiro J, Nakano M, Kikutani T, Konishi K. Development of rapid oral bacteria detection apparatus based on dielectrophoretic impedance measurement method. IET Nanobiotechnol. 2011;5:25-31.

30. Ishihama Y, Oda Y, Tabata T, Sato T, Nagasu T, Rappsilber J, et al. Exponentially modified protein abundance index (emPAl) for estimation of absolute protein amount in proteomics by the number of sequenced peptides per protein Mol Cell Proteom MCP. 2005;4:1265-72.

31. Pedersen AM, Bardow A, Jensen SB, Nauntofte B. Saliva and gastrointestinal functions of taste, mastication, swallowing and digestion. Oral Dis. 2002:8:117-29.

32. Humphrey SP, Williamson RT. A review of saliva: normal composition, flow, and function. J Prosthet Dent. 2001;85:162-9.

33. Villa A, Connell CL, Abati S. Diagnosis and management of xerostomia and hyposalivation. Ther Clin Risk Manag. 2014;11:45-51.

34. Ganeshnarayan K, Velliyagounder K, Furgang D, Fine DH. Human salivary cystatin SA exhibits antimicrobial effect against Aggregatibacter actinomycetemcomitans. J Periodontal Res. 2012:47:661-73.

35. Ito T, Komiya-Ito A, Arataki T, Furuya Y, Yajima Y, Yamada S, et al. Relationship between antimicrobial protein levels in whole saliva and periodontitis. J Periodontol. 2008;79:316-22.

36. Yang H-W, Huang $Y-F$, Chou M-Y. Occurrence of Porphyromonas gingivalis and Tannerella forsythensis in periodontally diseased and healthy subjects. J Periodontol. 2004;75:1077-83.

37. Abe N, Kadowaki T, Okamoto K, Nakayama K, Ohishi M, Yamamoto K. Biochemical and functional properties of lysine-specific cysteine proteinase (Lysgingipain) as a virulence factor of Porphyromonas gingivalis in periodontal disease. J Biochem (Tokyo). 1998;123:305-12.

38. Alves MB, Motta ACF, Messina WC, Migliari DA. Saliva substitute in xerostomic patients with primary Sjögren's syndrome: a single-blind trial. Quintessence Int Berl Ger. 1985;2004(35):392-6.

39. van Steenberghe D, Van den Eynde E, Jacobs R, Quirynen M. Effect of a lactoperoxidase containing toothpaste in radiation-induced xerostomia. Int Dent J. 1994:44:133-8.

40. Banoczy J, Dombi C, Czegledly A, Sari K. A clinical study with lactoperoxidasecontaining gel and toothpaste in patients with dry mouth syndrome. J Clin Dent. 1994:5:65-9.

41. Kirstilä $V$, Lenander-Lumikari $M$, Söderling $E$, Tenovuo J. Effects of oral hygiene products containing lactoperoxidase, lysozyme, and lactoferrin on the composition of whole saliva and on subjective oral symptoms in patients with xerostomia. Acta Odontol Scand. 1996;54:391-7.

\section{Publisher's Note}

Springer Nature remains neutral with regard to jurisdictional claims in published maps and institutional affiliations. 